\title{
A Case Report: Alprazolam Therapy in A Dextra Fronto-Parietal Meningioma Patient With Anxiety Disorders
}

\section{Efektivitas Alprazolam Pada Pasien Meningioma Fronto-Parietal Dextra Dengan Gangguan Cemas}

\author{
Prajogo Wibowo, Prawesty Diah Utami* \\ Kedokteran, Fakultas Kedokteran, Universitas Hang Tuah Surabaya, Jl. Gadung No 1, Komplek Barat RS Angkatan Laut \\ Dr. Ramelan, Wonokromo, Surabaya, 60111, Jawa Timur, Indonesia. Tel.: (031) 8433626
}

Meningiomas in the frontoparietal lobe may cause anxiety disorders and panic attacks. While alprazolam is one of the most widely used medications for anxiety disorders, long-term use may result in adverse side effects (withdrawal and rebound effects). This case study aims to describe the efficacy of long-term alprazolam administration in patients with meningiomas for regulating anxiety disorders. Case report:The asymmetrical face is the primary concern of a 65-year-old female when she is anxious. The results of the physical assessment and laboratory tests are within normal ranges. However, The HARS procedure showed moderate anxiety, and the CT scan revealed a meningioma in the right frontoparietal lobe. To regulate patient anxiety disorders, doctors give alprazolam $0.5 \mathrm{mg}$ per day single dose for 4 months and tapering off for 3 months. Conclusion: Long-term administration of alprazolam in these patients can reduce the patient's anxiety disorder without causing withdrawal or rebound effects. A low dosage of alprazolam, a mild level of anxiety illness, and a slow tapering off phase were factors that contributed to the effectiveness of alprazolam treatment to suppress anxiety symptoms in this situation.

Keywords: alprazolam, anxiety disorder, meningiomas

Meningioma di lobus fronto-parietalis fase awal dapat menyebabkan munculnya gangguan neuropsikiatri seperti gangguan kecemasan dan serangan panik. Alprazolam menjadi salah satu obat yang paling sering digunakan untuk mereduksi gangguan kecemasan, namun penggunaan jangka panjang dapat memicu efek samping (withdrawl dan rebound effect). Laporan kasus ini bertujuan untuk mendeskripsikan serta menguraikan efektivitas pemberian alprazolam jangka panjang untuk meregulasi gangguan kecemasan pada pasien dengan meningioma. Laporan kasus: seorang perempuan, 65 tahun, keluhan utama muka yang asimetris ketika mengalami kecemasan. Pemeriksaan fisik dan pemeriksaan laboratorium dalam batas normal, namun pemeriksaan indeks kecemasan menggunakan metode HARS menunjukkan gangguan kecemasan yang moderate, pemeriksaan CT scan menunjukkan adanya massa meningiomadi lobus frontoparietal dextra. Untuk mere- 
gulasi gangguan kecemasan yang diderita pasien, dokter memberikan terapi alprazolam $0.5 \mathrm{mg}$ per hari single dose selama 4 bulan dan tapering off selama 3 bulan. Kesimpulan: Pemberian alprazolam jangka panjang pada pasien tersebut dapat menekan gangguan kecemasan pasien tanpa menimbulkan efek withdrawl maupun rebound effect. Faktor yang berperan keberhasilan terapi alprazolam untuk menekan gangguan kecemasan pada kasus ini dikaitkan dengan dosisalprazolam yang relatif rendah, tingkat gangguan kecemasan yang tidak berat, dan proses tapering off yang berjalan secara bertahap.

Kata Kunci: alprazolam, gangguan kecemasan, meningioma 


\section{PENDAHULUAN}

Meningioma merupakan tumor intrakranial Loe and Maliawan (2019), angka kejadiannya mencapai 25\% dari tumor intrakranial primer Hussain et al. (2015). Karakteristik tumor ini adalah umumnya bersifat jinak, pertumbuhannya lambat, angka kejadiannya meningkat seiring dengan pertambahan usia sehingga sering ditemui pada pasien lanjut usia, serta lebih banyak terdiagnosis pada pasien perempuan Kalasauskas et al. (2020). Berbagai kelainan neurologis fokal (hemiparesis, defisit sensorik, dan afasia) timbul akibat keberadaan tumor otak baik primer atau metastasis. Gejala yang berbeda ditemukan pada kasus meningioma, terutama yang menekan lobus frontal tidak menghasilkan gejala apa pun selain perubahan progresif pada kepribadian dan kecerdasan sampai massa tumor membesar secara signifikan, sehingga dikenal dengan istilah "silent tumor" Hussain et al. (2015). Studi sebelumnya menyatakan bahwa meningioma terkait dengan munculnya gangguan kecemasan serta depresi secara signifikan Goebel and Mehdorn (2012); Yakhmi et al. (2015). Pasien dengan tumor semacam itu sering kali dirujuk terlebih dahulu ke psikiater, dan diagnosis yang benar mungkin muncul jika tumor telah membesar dan mulai menekan jaringan otak.

Alprazolam adalah obat triazolobenzodiazepine yang paling sering digunakan dalam terapi psikiatris, karena potensinya yang tinggi dan telah disetujui penggunaanya oleh USA Food and Drug Administration (FDA) sebagai pengobatan gangguan kecemasan dan panic disorder Aitdaoud et al. (2018). Terbitnya persetujuan FDA didasarkan pada hasil studi dua uji klinis acak berskala besar yang membuktikan efikasi obat jangka pendek dan tolerabilitas yang signifikan secara klinis dibandingkan dengan plasebo Ballenger et al. (1988); Klerman (1988). Obat ini bekerja melalui kemampuannya untuk menurunkan aktivitas kimiawi otak dengan berikatan pada reseptor Y-aminobutyric acid (GABA) Chowdhury et al. (2016).

Disamping efektivitasnya yang sangat poten dan cepat untuk menanggulangi gangguan psikiatri, penggunaan alprazolam jangka panjang (lebih dari 2 - 4 minggu) memicu efek withdrawal dan abstinesia Louvet et al. (2015). Withdawal effect merupakan suatu kondisi dimana fungsi fisiologis endogen tubuh tidak mampu bekerja seperti semula setelah penghentian penggunaannya, sehingga memperparah kondisi klinis penderita dari sebelum menggunakan alprazolam Ait-daoud et al. (2018). Hal ini disebabkan karena terhambatnya efek inhibisi sistem syaraf pusat disisi lain efek obat eksogen telah hilang akibat penghentian konsumsi obat tersebut. Hal tersebut memicu aktivitas kimiawi otak tanpa adanya hambatan fisiologis endogen, sehingga memicu gangguan yang mirip dengan kondisi sebelum menggunakan obat, yang dikenal dengan istilah abstinensia. Jika penderita kembali mengkonsumsi obat tersebut, maka gejala tersebut akan hilang, sehingga fenomena tersebut memicu terjadinya adiksi atau ketergantungan secara fisik dan psikologis Louvet et al. (2015); Ait-daoud et al. (2018).

Beberapa hal penting yang akan diungkap dalam laporan kasus ini adalah keefektifan penggunaan alprazolam jangka panjang untuk mereduksi gejala gangguan kecemasan penderita meningioma frontoparietal dextra.

\section{LAPORAN KASUS}

Seorang perempuan, berusia 65 tahun, suku Jawa, telah menikah, latar belakang sosio ekonomi menengah, profesi ibu rumah tangga pada saat dirujuk ke unit rawat jalan poli syaraf dan psikiatri dengan riwayat keluhan perubahan perilaku (muka asimetris jika penderita mengalami kecemasan) sejak 7 bulan yang lalu. Autoanamnesa mendalam menunjukkan bahwa penderita mengalami ketakutan akan kematian yang tidak terkontrol sehingga membuat penderita menarik diri dari lingkungan sosial, gelisah, mudah tersinggung/ mudah marah, kelelahan dengan aktivitas ringan, sulit berkonsentrasi, penurunan daya ingat dan sulit untuk tidur. Pada saat tertentu, penderita juga merasa berdebar - debar, berkeringat lebih ketika merasa ketakutan akan sesuatu. Terdapat riwayat hipertensi (pasien rutin mengkonsumsi obat anti hipertensi dari dokter yaitu amlodipin) Tidak ada riwayat penyakit kejiwaan, riwayat penyakit sistemik dan metabolik atau riwayat penyakit keluarga sebelumnya, tidak ada riwayat penyalahgunaan zat. Pemeriksaan fisik menunjukkan tekanan darah 119/79, nadi $84 \mathrm{kali} /$ menit, frekuensi pernafasan $16 \mathrm{kali} / \mathrm{menit}$, suhu aksial $36,8^{\circ} \mathrm{C}$, dan pada pemeriksaan neurologis tidak ditemukan adanya kelainan (muka yang asimetris tidak ditemukan saat pemeriksaan).Pada pemeriksaan HAM-A (Hamilton Anxiety Rating Scale) untuk menilai tingkat kecemasan seseorang melalui pengamatan dan wawancara Ramdan (2018); Slater et al. (2019). Terdapat 14 item pertanyaan menunjukkan bahwa penderita mengalami perasaan cemas, tegang, ketakutan yang tidak jelas, mengalami gangguan tidur, gangguan daya ingat, depresi, gejala somatik otot - sensorik, gangguan kardiovaskular, gangguan pernafasan serta perilaku saat wawancara menunjukkan raut muka tegang, kening selalu dikerutkan. Interpretasi pemeriksaan HARS terbagi menjadi 3 kelompok : (1) ringan jika skor <17; (2) sedang jika skor 17-24; (3) Berat jika skor 25-30. Skor HARS mencapai angka 19 artinya penderita termasuk dalam gangguan kecemasan dengan skala sedang/ moderate Ramdan (2018); Slater et al. (2019)

Hasil pemeriksaan fisik dan pemeriksaan neurologis tidak menunjukkan adanya kelainan. Hasil pemeriksaan laboratorium darah lengkap dan analisis kimia darah (BUN/ serum kreatinin, AST/ALT, bilirubin dalam batas normal). Pemeriksaan CT Scan kepala menunjukkan lesi hiperdens (56-63 HU) batas tegas, tepi regular, disertai multiple kalsifikasi di dalamnya (17\% HU) pada lobus frontalis kanan disertai minimal perifocal edema di sekitarnya. Lesi tersebut terpisah pada os. calvaria di sekitarnya. Kesimpulan hasil CT-scan pada Gambar 1 menunjukkan adanya calcified meningioma frontoparietal kanan dengan ukuran $2 \times 3 \mathrm{~cm}$.

Berdasarkan anamnesa, pemeriksaan fisik dan hasil pemeriksaan penunjang, dokter memberikan obat alprazolam 
$0,5 \mathrm{mg}$ dosis sekali sehari malam hari selama 4 bulan untuk penanganan gangguan kecemasan yang diderita pasien. Monitoring gejala kecemasan pasien membaik dan terkontrol setelah konsumsi alprazolam (diakhir pemberian terapi menunjukkan penurunan nilai HARS yaitu mencapai skor 4 yang menunjukkan gangguan kecemasan yang ringan, serta mendekati nilai normal). Proses terapi alprazolam dilanjutkan dengan tahap tapering offyang berjalan selama tiga bulan. Proses tapering off dilakukan dengan reduksi dosis pemakaian alprazolam secara bertahap dan selama proses tersebut, pasien tidak menunjukkan gejala withdrawl maupun rebound effect. Dokter juga menyarankan dilakukan pembedahan terkait diagnosis meningioma, namun pasien menolak untuk dilakukan tindakan tersebut.

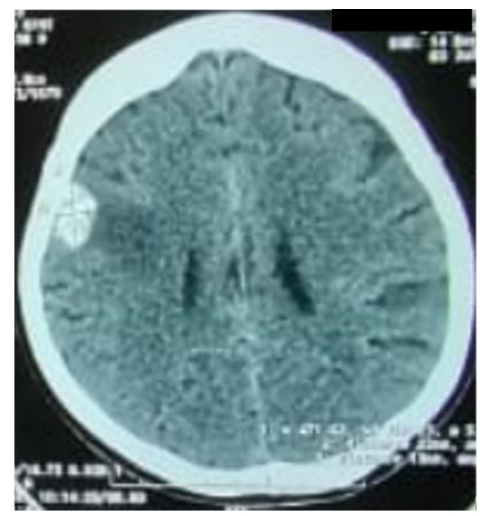

GAMBAR 1. Hasil CT-scan Pasien

\section{HASIL DAN PEMBAHASAN}

Tumor intracranial tidak hanya menyebabkan defisit neurologis namun dapat menginisiasi timbulnya berbagai gangguan psikiatri. Kasus ini merupakan manifestasi gangguan psikiatri dari tumor lobus fronto-parietal yang muncul pada awalnya tanpa disertai defisit neurologis. Tumor intrakranial, terutama meningioma frontal, dapat diiringi dengan berbagai gangguan psikiatri yang meliputi kecemasan, depresi, hipomania, dan skizofrenia. Sakit kepala, papilledema, dan tanda-tanda neurologis fokal hanya dapat berkembang jika tumor telah mencapai stadium lanjut Hussain et al. (2015); Yakhmi et al. (2015).

Munculnya gejala neuropsikiatri pada kasus brain tumor berkorelasi dengan terjadinya edema cerebri. peningkatan tekanan intrakranial dan diaschisis (mempengaruhi koneksi ke area otak yang jauh) yang mengganggu intracerebral pathway di otak Subramoniam et al. (2015). Letak tumor juga mempengaruhi gejala neuropsikiatri yang muncul. Pada studi yang dilakukan oleh Subramoniam et al. (2015) menyatakan bahwa tumor di area frontoparietal menyebabkan munculnya depresi dan kecemasan yang progresif Subramoniam et al. (2015); Trevizol et al. (2019). Hal ini sesuai dengan gambaran klinis penderita dalam laporan kasus ini.

Adanya gejala neuropsikiatri yang tidak spesifik, membuat penegakkan diagnosis dini pada kasus tersebut menjadi sulit. Oleh karena itu, ketika menangani penderita yang berusia lanjut tanpa riwayat gangguan kejiwaan, mengalami perubahan psikologis yang progresif, maka dokter atau klinisi harus mempertimbangkan untuk menyingkirkan gangguan organik di otak yang dapat menjadi salah satu penyebabnya. Gejala seperti sakit kepala, kehilangan ingatan, deperasi dan kecemasan yang tidak terkontrol dan progresif perkembangannya, harus dipertimbangkan adanya penyakit organik seperti meningioma frontal dan pemeriksaan imaging (baik CT scan atau MRI) harus dilakukan. Diagnosis dini sangat penting berkaitan dengan perawatan lebih lanjut dan kualitas hidup yang lebih baik.

Alprazolam merupakan salah satu obat pilihan dalam penanganan gangguan cemas selain kelompok obat selective serotonin reuptake inhibitors (SSRIs) dan serotoninnorepinephrine reuptake inhibitors (SNRIs) Louvet et al (2015). Kecepatan masuk dalam jaringan lipid otak dipengaruhi sifat kelarutannya dalam lipid. Obat ini mampu menekan sistem limbik, batang otak serta berikatan dengan kompleks reseptor GABA-klorida, sehingga menjadi neurotransmitter penghambat eksitabilitas sistem syaraf pusat.Alprazolam dapatmeningkatkan efek GABA yang mengakibatkan hipnotik, penenang, anxiolytic, antikonvulsan,dan pelemas otot Louvet et al. (2015); Chowdhury et al. (2016). Berbagai uji klinis membuktikan bahwa penggunaan jangka pendek telah terbukti dapat menekan semua gejala gangguan kecemasan dan serangan panik. Penggunaan jangka panjang obat ini masih menjadi kontroversi, dan tidak direkomendasikan, meskipun dalam kenyataannya sering diterapkan oleh para klinisi. Konsumsi selama dua bulan atau lebih, dinyatakan sebagai terapi jangka panjang.Terapi jangka panjang alprazolam, dapat memicu terjadinya gejala withdrawl/ ketergantungan fisiologis dan psikologis ditandai dengan kondisi penarikan diri, dan keengganan untuk mengurangi atau menghentikan penggunaannya meskipun secara obyektif dianggap kurang efektif. Alprazolam juga dapat memicu gejala rebound, yang mengarah ke peningkatan dosis dan perbaikan gejala yang bersifat sementara Ogbonna and Lembke (2017); AitDaoud et al. (2018).

Pada kasus ini, alprazolam digunakan untuk terapi jangka panjang (lebih dari dua bulan) dengan dosis yang paling rendah ( $0,5 \mathrm{mg}$ sekali sehari). Selama pemakaian dan proses penghentian/ tapering off obat tidak dilaporkan gejala withdrawl maupun rebound effect. Beberapa kemungkinan yang menjadi penyebab tidak munculnya withdrawl maupun rebound effect dikaitkan dengan dosis terendah yang digunakan. Dosis alprazolam untuk penanganan gangguan cemas berkisar dari 0.5 - $3 \mathrm{mg}$ Verster and Volkerts (2004). Tingkat kecemasan level medium sebelum pemberian terapi serta penurunan level kecemasan selama pemberian terapi juga menjadi salah satu faktor penyebab.Proses tapering off yang cukup panjang secara pelan - pelan, tidak adanya penyakit penyerta yang menghambat eliminasi dan metabo- 
lisme obat juga diduga dapat mencegah efek withdrawl maupun rebound effect Verster and Volkerts (2004).

\section{KESIMPULAN}

Pemberian alprazolam pada gangguan kecemasan dengan kelainan primer meningioma membutuhkan monitoring ketat. Karena pemberiannya bersifat long term, mengingat gejala yang muncul bersifat kronis seiring dengan perkembangan massa tumor. Pemberian alprazolam jangka panjang meningkatkan resiko terjadinya efek withdrawl serta rebound. Pada kasus ini menunjukkan bahwa pemberian dosis rendah alprazolam, level gangguan kecemasan yang tidak berat sebelum pemberian pengobatan, respon perbaikan gejala neuropsikiatri setelah pemberian obat serta proses tapering off yang bertahap dan pelan;kemungkinan dapat mencegah munculnya withdrawl dan rebound effect dari alprazolam.

\section{KONTRIBUSI PENULIS}

Penulis pertama berkontribusi dalam pengumpulan data pasien dan mencari artikel yang dijadikan referensi. Penulis kedua berperan sebagai penyusun artikel dan coresponding author.

\section{PENDANAAN}

Pendanaan penyusunan artikel dan publikasi ditanggung oleh penulis dan FK Universitas Hang Tuah, Surabaya.

\section{UCAPAN TERIMA KASIH}

Penulis mengucapkan terimakasih kepada pada FK Universitas Hang Tuah serta segenap pihak yang membantu dalam penyusunan artikel ilmiah ini.

\section{REFERENSI}

Ait-Daoud, N., Hamby, A. S., Sharma, S., \& Blevins, D. (2018). A Review of Alprazolam Use, Misuse, and Withdrawal. Journal of Addiction Medicine, 12(1), 4-10. doi: 10.1097/ADM.0000000000000350

Ballenger, J. C., Burrows, G. D., Dupont, R. L., Lesser, I. M., Noyes, R., Pecknold, J. C., Rifkin, A., \& Swinson, R. P. (1988). Alprazolam in Panic Disorder and Agoraphobia: Results From a Multicenter Trial: I. Efficacy in Short-term Treatment. Archives of General Psychiatry, 45(5), 413-422. doi: 10.1001/archpsyc. 1988.01800290027004

Chowdhury, Z. S., Morshed, M. M., Shahriar, M., Bhuiyan, M. A., Mohd, S., Islam, A., Shahdaat, M., \& Sayeed, B. (2016). The Effect of Chronic Alprazolam Intake on Memory, Attention, and Psychomotor Performance in Healthy Human Male Volunteers. Behavioural Neurology, 2016, 1-9. Retrieved from https://www.hindawi.com/journals/bn/2016/3730940/

Goebel, S., \& Mehdorn, H. M. (2012). Development of anxiety and depression in patients with benign intracranial meningiomas: a prospective long-term study. Supportive Care in Cancer -, 1(1), 1-9. doi: 10.1007/s00520-012-1
$1675-5$

Hussain, T., Shafat, M., \& Bhat, J. A. (2015). Frontal lobe meningioma masquerading as depressive disorder. African Journal of Psychiatry (South Africa), 18(6). doi: 10.4172/2378-5756.1000328

Kalasauskas, D., Keric, N., Ajaj, S. A., Cube, L. von, Ringel, F., \& Renovanz, M. (2020). Psychological burden in meningioma patients under a wait-andwatch strategy and after complete resection is high - results of a prospective single center study. Cancers, 12(12), 1-13. doi: 10.3390/cancers12123503

Klerman, G. L. (1988). Overview of the Cross-National Collaborative Panic Study: I. Efficacy in Short-term Treatment. Archives of General Psychiatry, 45(5), 407-412. doi: 10.1001/archpsyc.1988.01800290021003

Loe, M. L., \& Maliawan, S. (2019). Spontaneous recovery of Medial Prefrontal Syndrome following Giant Olfactory Groove Meningioma resection: A case report. Bali Medical Journal, 8(2), 380. doi: 10.15562/bmj.v8i2.1454

Louvet, S., Ischayek, M., \& Danoff, R. (2015). The Current Role of Long-Term Benzodiazepines for the Treatment of Generalized Anxiety. 20 Osteopathic Family Physician, 7(1), 19-25. Retrieved from https://ofpjournal.com/index.php/ofp/article/view/364

Ogbonna, C. I., \& Lembke, A. (2017). Tapering Patients Off of Benzodiazepines. American family physician, 96(9), 606-610. Retrieved from https://pubmed.ncbi.nlm.nih.gov/29094883/

Ramdan, I. M. (2018). Reliability and Validity Test of the Indonesian Version of the Hamilton Anxiety Rating Scale ( HAM-A ) to Measure Work-related Stress in Nursing Design of Study and Participants. Journal Ners, 14(1), 3340. Retrieved from https://e-journal.unair.ac.id/JNERS/article/view/10673

Slater, P., Bunting, B., Hasson, F., Al-Smadi, A. M., Omar Salem Gammouh, A A., \& Jordan, D. (2019). An Examination of Factor Structure of the Hamilton Anxiety Rating Scale in a An Examination of Factor Structure of the Hamilton Anxiety Rating Scale in a Non-Clinical Persian Sample. International Journal of Research in Nursing, 10(1.9), 1-10. doi: 10.3844/ijrnsp.2019.1.9

Subramoniam, M., Ting, M. B., Farah, T., \& Ugur, U. (2015). Psychiatric aspects of brain tumors: A review. World Journal of Psychiatry, 5(3), 273-285. doi: 10.5498/wjp.v5.i3.273

Trevizol, A. P., Cerqueira, R. D. O., Brietzke, E., \& Cordeiro, Q. (2019). Newonset psychiatric symptoms following ntracranial meningioma in a patient with schizophrenia: A case study. Revista Brasileira de Psiquiatria, 41(1), 91-92. doi: 10.1590/1516-4446-2018-0055

Verster, J. C., \& Volkerts, E. R. (2004). Clinical Pharmacology, Clinical Efficacy, and Behavioral Toxicity of Alprazolam: A Review of the Literature. CNS Drug Reviews, 10(1), 45-76. doi: 10.1111/j.15273458.2004.tb00003.x

Yakhmi, S., Sidhu, B. S., Kaur, J., \& Kaur, A. (2015).Diagnosis of frontal meningioma presenting with psychiatric symptoms. Indian Journal of Psychiatry, 57(1), 91-93. doi: 10.4103/0019-5545.148534

Conflict of Interest Statement: The authors declare that the research was conducted in the absence of any commercial or financial relationships that could be construed as a potential conflict of interest.

Copyright () 2021 Wibowo and Utami. This is an open-access article distributed under the terms of the Creative Commons Attribution License (CC BY). The use, dis- tribution or reproduction in other forums is permitted, provided the original author(s) and the copyright owner(s) are credited and that the original publication in this jour- nal is cited, in accordance with accepted academic practice. No use, distribution or reproduction is permitted which does not comply with these terms. 